\title{
Gene Amplification Abnormality
}

National Cancer Institute

\section{Source}

National Cancer Institute. Gene Amplification Abnormality. NCI Thesaurus. Code C45581.

An increase in the copy number of a particular gene. This type of abnormality can be either inherited or somatic. 